Research article

\title{
Adaptations to iron deficiency: cardiac functional responsiveness to norepinephrine, arterial remodeling, and the effect of beta-blockade on cardiac hypertrophy Lexa Rae Turner, Daniel Aaron Premo, Brett Jason Gibbs, Megan Lesley Hearthway, Madelyne Motsko, Andrea Sappington, LeeAnn Walker, Michael Eugene Mullendore and Herbert George Chew Jr*
}

Address: Department of Biological Sciences R.A. Henson School of Science and Technology Salisbury State University Salisbury, MD 21801, USA

E-mail: Lexa Rae Turner - lexssu@ hotmail.com; Daniel Aaron Premo - dap3506@students.ssu.edu; Brett Jason Gibbs - BrettG@Koons.com; Megan Lesley Hearthway - mlh6756@students.ssu.edu; Madelyne Motsko - madge289@aol.com;

Andrea Sappington - asappington@hotmail.com; LeeAnn Walker - lawillig@aol.com; Michael Eugene Mullendore - md_2be05@yahoo.com;

Herbert George Chew* - budchew@mac.com

${ }^{*}$ Corresponding author

This article is available from: http://www.biomedcentral.com/I472-6793/2/I

(c) 2002 Turner et al; licensee BioMed Central Ltd. Verbatim copying and redistribution of this article are permitted in any medium for any non-commercial purpose, provided this notice is preserved along with the article's original URL. For commercial use, contact info@biomedcentral.com

\begin{abstract}
Background: Iron deficiency (ID) results in ventricular hypertrophy, believed to involve sympathetic stimulation. We hypothesized that with ID I) intravenous norepinephrine would alter heart rate (HR) and contractility, 2) abdominal aorta would be larger and more distensible, and 3) the beta-blocker propanolol would reduce hypertrophy.
\end{abstract}

Methods: I) $30 \mathrm{CD}$ rats were fed an ID or replete diet for I week or I month. Norepinephrine was infused via jugular vein; pressure was monitored at carotid artery. Saline infusions were used as a control. The pressure trace was analyzed for HR, contractility, systolic and diastolic pressures. 2) Abdominal aorta catheters inflated the aorta, while digital microscopic images were recorded at stepwise pressures to measure arterial diameter and distensibility. 3) An additional 10 rats (5 ID, 5 control) were given a daily injection of propanolol or saline. After I month, the hearts were excised and weighed.

Results: Enhanced contractility, but not HR, was associated with ID hypertrophic hearts. Systolic and diastolic blood pressures were consistent with an increase in arterial diameter associated with ID. Aortic diameter at $100 \mathrm{mmHg}$ and distensibility were increased with ID. Propanolol was associated with an increase in heart to body mass ratio.

Conclusions: ID cardiac hypertrophy results in an increased inotropic, but not chronotropic response to the sympathetic neurotransmitter, norepinephrine. Increased aortic diameter is consistent with a flow-dependent vascular remodeling; increased distensibility may reflect decreased vascular collagen content. The failure of propanolol to prevent hypertrophy suggests that ID hypertrophy is not mediated via beta-adrenergic neurotransmission. 


\section{Background}

The iron status of an individual may play an important role in cardiovascular health, with either an excess of iron (mainly the storage form ferritin) or iron deficiency leading to significant problems. Sullivan [1] has proposed that excess iron (i.e., any iron in the ferritin form) leads to formation of free radicals that can worsen ischemic myocardial injury and contribute to atherogenesis. This hypothesis has considerable experimental $[2,3]$ and epidemiological $[4,5]$ support. However, the "iron hypothesis" has not been universally accepted [6], and considerable debate on the role of iron overload on cardiovascular disease continues [7-10].

Iron deficiency has also been shown to lead to ventricular hypertrophy in developing rats [11-17]. While the mechanisms responsible for this hypertrophy have received little research attention, studies have documented an eccentric hypertrophic pattern [15-17] which has led investigators to suspect a ventricular volume overload at end diastole as a primary hypertrophic stimulus. The hypothesized volume load, if it occurs, does not result from a change in blood volume [18]. It has also been hypothesized that a chronic elevation in sympathetic nervous system activity is involved in iron deficiency-induced hypertrophy. Evidence to support this view includes the observations of increased levels of norepinephrine in plasma and urine, and decreased norepinephrine content in the iron deficient heart [19-22]. Rossi [23], after finding that reserpine administration prevented the development of this hypertrophy, even suggested that norepinephrine is the causal agent in the pathology. While little published research has subsequently focused on iron deficiency hypertrophy, there have been numerous studies investigating the role of sympathetic neurotransmission with cardiac hypertrophy induced via various methods (coronary artery ligation, chronic pressure overload, transgenic models, etc.). Most have demonstrated alterations in either plasma or heart norepinephrine content, and a de-sensitization of the beta-adrenergic receptors of the heart [24-33]. Recently, the alpha-adrenergic receptor has been shown in vitro to be an important modulator of ventricular hypertrophy. However, even in transgenic animal models overexpressing alpha receptors, the beta-adrenergic receptor appears to play an important role in hypertrophy development and the transition to heart failure [34,35]. Regardless of which receptors are involved in the various forms of hypertrophy, the sympathetic nervous system does appear to play a role in most, if not all, forms of cardiac hypertrophy, and much remains to be done in this area [36].

Almost no attention has been paid to the peripheral vascular consequences of iron deficiency [37]. With iron deficiency, the poor oxygen-carrying capacity of the blood must be offset in order for the animal to develop to full maturity. Therefore, the chronic sympathetic activation associated with iron deficiency should result in increased cardiac output. In turn, flow through the major arterial network would be enhanced in an attempt to maintain near normal oxygen delivery. Kamiya and Togawa [38] have found that increased flow stimulates remodeling of an artery to a larger diameter through an endothelial dependent mechanism. It has yet to be demonstrated whether iron deficiency will stimulate a similar arterial remodeling.

Collagen is an integral component of the arterial wall, providing rigidity and support. Iron is necessary in the synthesis of collagen [39], and collagen content has been shown to be reduced in iron deficient hearts [40]. If this is similarly true for arteries in iron deficient animals, a significant increase in distensibility would result, altering the normal pressure-volume relationship.

We investigated three hypotheses using anesthetized rats. First, we hypothesized that in iron deficient rats, intravenous norepinephrine would cause an altered cardiovascular response, either in heart rate or rate of arterial pressure generation (contractility, $\mathrm{dp}^{\bullet} \mathrm{dt}^{-1}$ ). Second, we hypothesized that iron deficient arteries would be larger and more distensible than in iron replete controls. Finally, we hypothesized that a daily injection of the beta-adrenergic antagonist propanolol would significantly reduce the development of ventricular hypertrophy.

Our results suggest that iron deficient, hypertrophic hearts display a hyper-sensitive inotropic, but not chronotropic, response to norepinephrine. Second, abdominal aortas from iron deficient rats display not only increased diameters, but also significant increases in distensibility. Finally, propanolol injections do not prevent the development of iron deficient cardiac hypertrophy, drawing into question the potential causal relationship between beta-adrenergic neurotransmission and this form of hypertrophy.

\section{Results and Discussion Body weight, heart weight, and hematocrit (Experiments I and 2)}

Rat growth rate is shown in figure 1 . There were no differences between any of the experimental groups (see Materials and Methods) until the animals reached 45 days of age, after which, iron deficient rats are of less mass than controls $(*, p<0.05)$. Figure 1 also shows the final mean body mass of the four experimental groups. Iron deficient and control groups more than doubled their body mass from 1 week to 1 month on the respective diets $(\dagger, \mathrm{p}<$ $0.0001)$. The control rats also had a significantly greater mass than the iron deficient rats $(\mathrm{p}=0.0004)$ in the one month group $(*, p=0.0006)$, but not at one week $(\mathrm{p}=$ 


\section{Growth Rates}
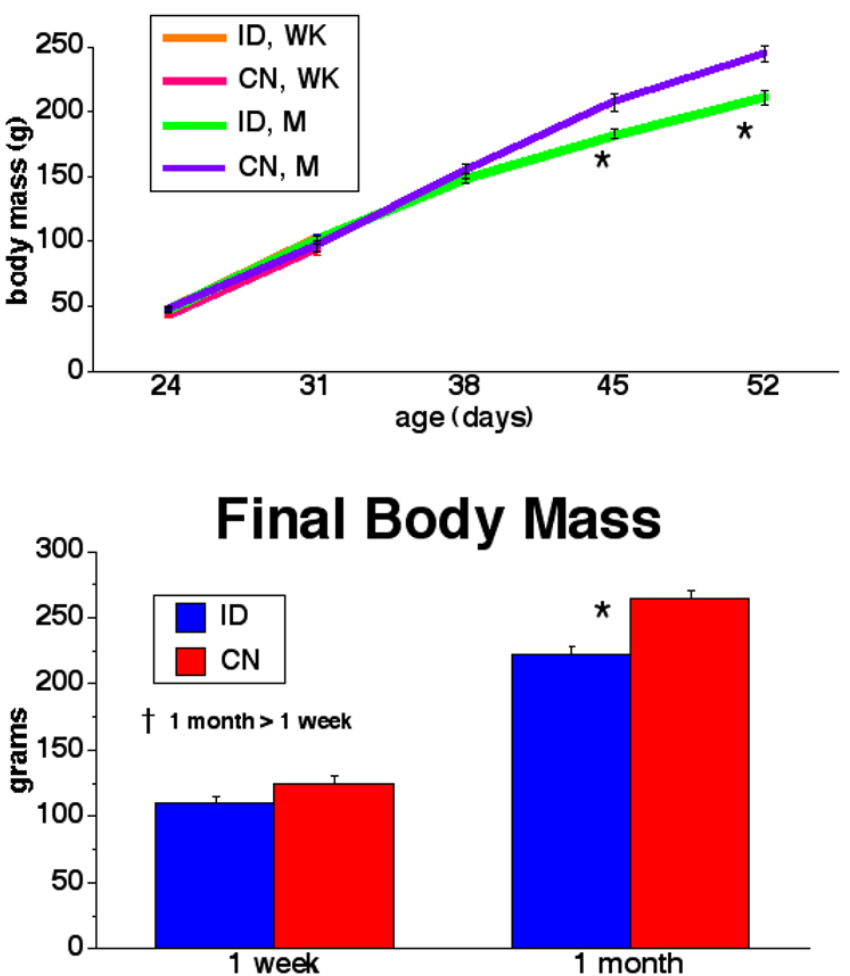

Figure I

Rat Growth Rate and Final Body Mass

0.1530). The control rats in this study increased mass at a rate similar to that published for the ad libitum fed CD rat $[41,42]$, suggesting growth was inhibited by iron deficiency. It is likely that growth inhibition is attributable to metabolic causes arising from both oxygen delivery and mitochondrial insufficiencies associated with iron deficiency [14]. The growth data for both the control and iron deficient groups are also similar to that reported for male Wistar rats fed an iron and copper deficient diet [15], but the iron deficient rats at 52 days of age were larger than reports of 10 week old Harlan Sprague-Dawley rats fed an AIN-76 iron deficient diet [17].

Heart mass increased significantly from 1 week to 1 month of the diets (figure $2, \dagger, \mathrm{p}<0.0001$ ). Diet group differences were not apparent at 1 week $(\mathrm{p}=0.8674)$, but the hearts of iron deficient rats were of greater mass at 1 month $(*, p=0.0357)$, indicating that the heart has undergone hypertrophy by this time. These differences remained significant after normalization of heart weight to body weight (data not shown). This time frame for development of hypertrophy is similar to previous findings with iron or copper deficiency [14-17,40,43].
Mean hematocrit levels (figure 2 bottom) of iron deficient
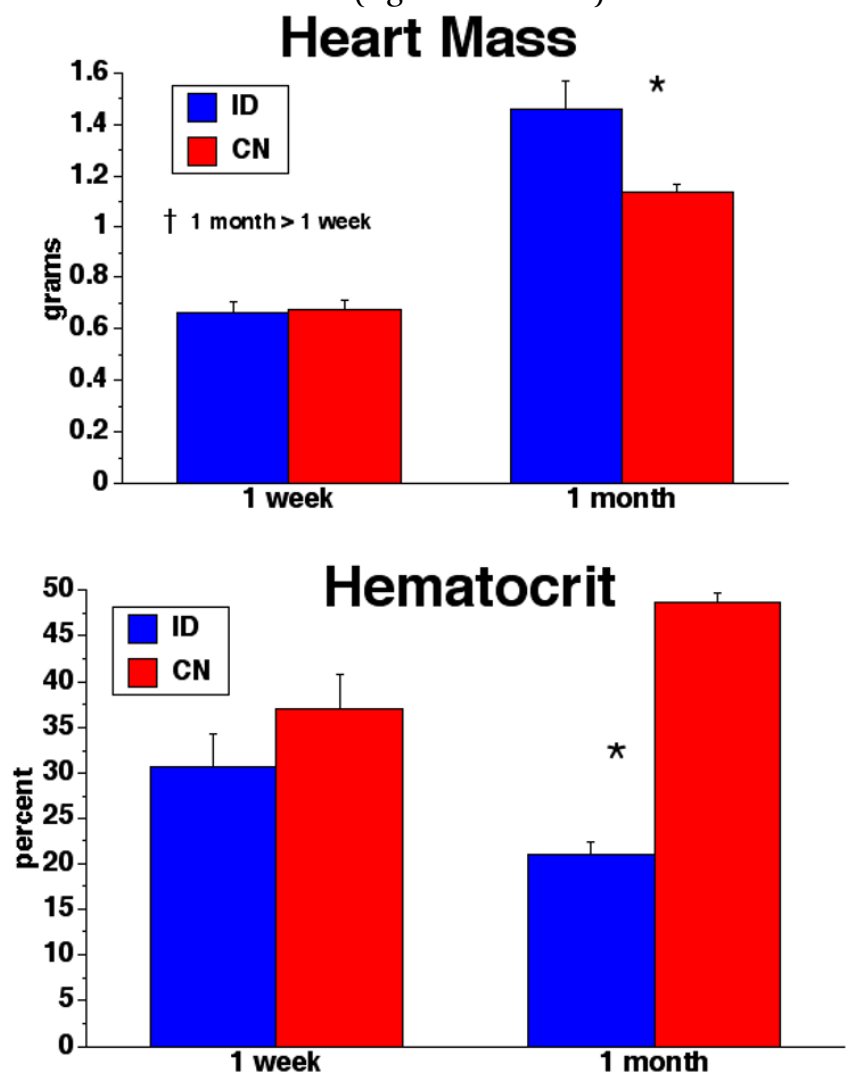

Figure 2

Heart mass and Hematocrit

animals were significantly less than controls after 1 month $(*, p<0.0001)$, but not 1 week $(\mathrm{p}=0.3102)$, of the respective diets. Many studies have documented significant hematocrit decreases after one month of an iron deficient diet $[14-17,40,43]$. However, few of these report data for 1 week, though one published study indicated a small but significant difference [15], and we have observed a group difference after 1 week of iron deficiency in another study (Mullendore, et. al., manuscript in progress). We speculate that the ability to create significant iron deficiency in this short time is dependent upon the purity of the iron deficient diet as well as individual animal differences. Nonetheless, examination of several time points during the progression of iron deficiency can potentially provide important insights into the development of resulting physiological alterations.

\section{Experiment I: Cardiodynamics}

In these experiments, an infusion of intravenous saline was used to ensure that the delivery method employed did not evoke a cardiovascular response. In all variables measured, which include heart rate and ventricular contractility (figure 3), systolic and diastolic pressures (figure 4), there 

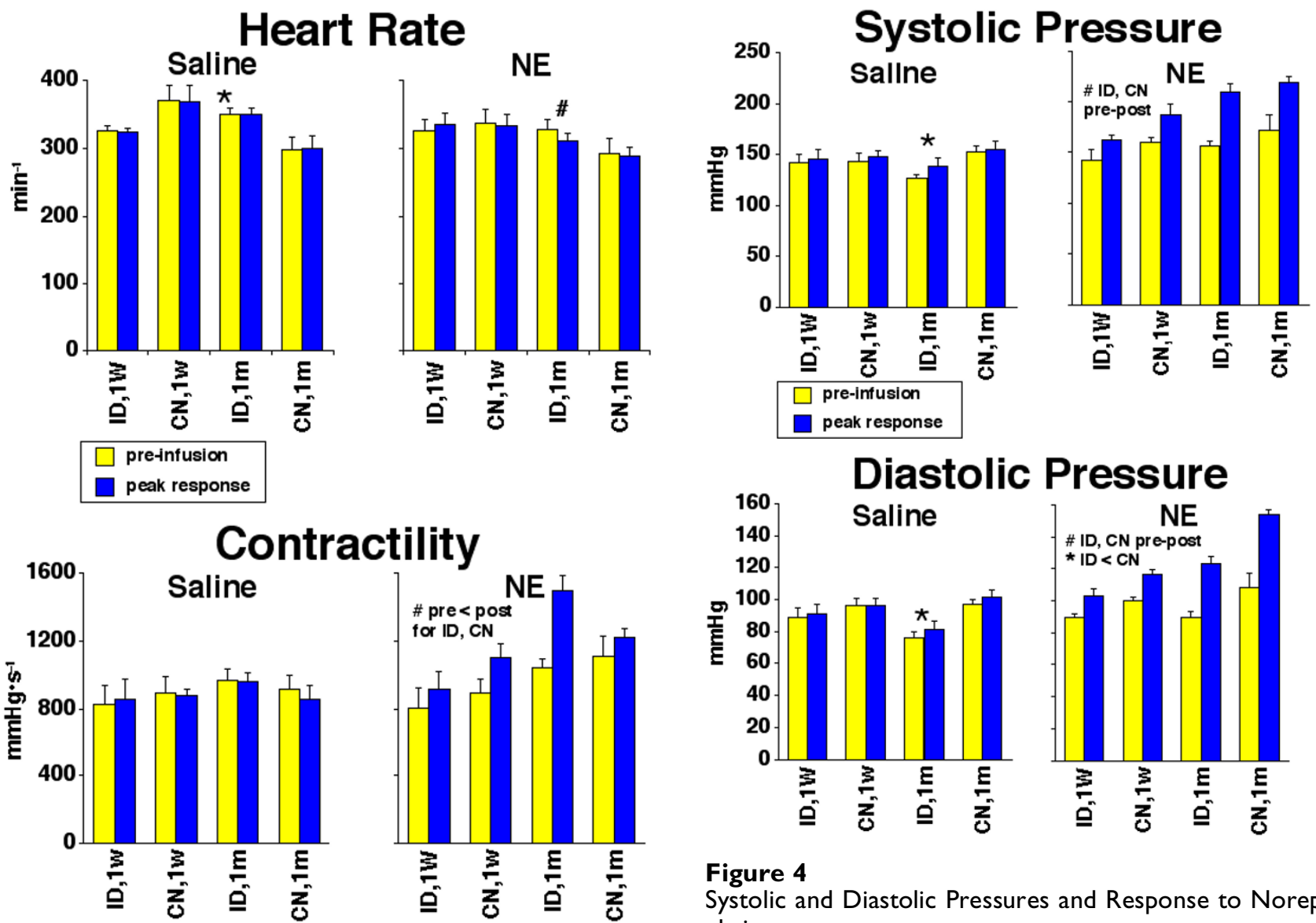

Figure 4

Systolic and Diastolic Pressures and Response to Norepinephrine

Figure 3

Heart Rate and Contractility and Response to Norepinephrine

were no differences between pre-infusion and peak responses to saline. Therefore, any differences seen with intravenous norepinephrine were attributable to the catecholamine and not the infusion per sé. Prior to the infusion of saline, group differences were already apparent between iron deficient and control rats at 1 month in heart rate $(*, \mathrm{p}=0.0025)$, systolic $(*, \mathrm{p}=0.0041)$ and diastolic pressure $(*, \mathrm{p}=0.0020)$, but not contractility $(\mathrm{p}=$ $0.6373)$. We believe these pressure changes are associated with vascular remodeling, as discussed below.

Figure 3 also shows heart rate and contractility immediately prior to, and at peak response to, intravenous norepinephrine infusions. Prior to norepinephrine infusion, there were no differences between iron deficient and control groups within each duration in either heart rate or contractility $(\mathrm{p}>0.05)$. Heart rate was unchanged from pre-norepinephrine infusion to peak response $(\mathrm{p}=$ 0.3905 ). The only difference in peak heart rate response to norepinephrine was the iron deficient group at 1 month $(\#, \mathrm{p}=0.0272)$, which showed a significant decrease.

Contractility was significantly increased for both control $(\#, \mathrm{p}=0.0259)$ and iron deficient $(\#, \mathrm{p}=0.0008)$ groups from pre-infusion to peak response. At one month, contractility for iron deficient rats increased $43.71 \%$ upon norepinephrine infusion, while the control group at 1 month increased only $10.0 \%$.

Figure 3 demonstrates a unique response pattern to the sympathetic nervous system neurotransmitter, norepinephrine. For both control and iron deficient groups, the response to norepinephrine is to increase contractility in the absence of chronotropic increases. Cardiac output, therefore, would be expected to increase due to enhanced stroke volume, with an uncompromised filling time and a more powerful ventricular contraction. In fact, this pattern is even more exaggerated in the iron deficient animals at 1 month. Heart rate in this group was decreased, which allows the animal two potential advantages. First, ventricular filling time would be increased, potentially allowing for greater end diastolic and stroke volumes. This would be expected chronically to result in a eccentric hypertrophic pattern, a condition that we and others $[15,17]$ have found in iron deficient rat hearts. Second, 
the decrease in heart rate in iron deficient hearts when norepinephrine was infused would allow for longer myocardial perfusion time, which would compensate for the decreased oxygen carrying capacity of the blood and impaired mitochondrial function [14]. The iron deficient norepinephrine response compliments the finding of an increase in capillary lumenal volume in iron deficient hearts [15], which should also allow for better myocardial perfusion during diastole. Norepinephrine infusion resulted in a dramatic enhancement of contractility $(43.71 \%)$ in 1 month iron deficient rats when compared to 1 month control rats $(10.0 \%)$. By utilizing a hyper-sensitive response to sympathetic stimulation, coupled with an unchanged or lower heart rate, the iron deficient heart can potentially offset some of the oxygen delivery deficiencies of anemic blood without risking myocardial ischemia. These appear to be positive adaptations, at least short term, in response to a serious nutritional challenge. Iron deficient cardiac hypertrophy is not unique in this regard, as Lin has recently documented enhanced contractility without increased heart rate in hyper-sympathetic transgenic mice [34]. In contrast, there is a large body of evidence which suggests that cardiac hypertrophy which has progressed to the point of pathology, ultimately results in a decrease in contractility [25$27,29,30,32,33,44,45]$. We have not yet investigated whether the iron deficient heart will similarly lose the augmented contractility response in time.

It has been suggested in several papers that changes in sympathetic nervous system responsiveness may begin as a positive adaptation, but ultimately results in pathologic failure of the myocardium. For example, Engelhardt [46], in a study of mice genetically bred with an increase in beta-adrenergic receptor density, showed that increased contractility was an initial response, but by 35 weeks contractility was reduced by $50 \%$ and ejection fraction by $20 \%$. The genetically altered, hyper-adrenergic heart ultimately failed after initial enhancement of cardiac function.

Mukherjee and Spinale [47], in a recent review, concluded that with hypertrophy comes a decrease in cardiac contractility as a result of changes to the L-type $\mathrm{Ca}^{2+}$ channel. However, the authors noted that this adaptation, while generally present in a failing hypertrophied myocardium, is not necessarily present in less serious cardiac hypertrophies. Similarly, Tse [48] found that in compensated hypertrophy the population of beta-adrenergic receptors is relatively normal, but in heart failure, the beta receptors have both down-regulated and de-sensitized. Sheridan [49] and Iaccarino [35] came to a similar conclusion regarding heart failure and adrenergic down-regulation.
Figures 4 shows systolic and diastolic pressures before and after the norepinephrine infusion. There was a significant increase in systolic pressure for both the control $(*, \mathrm{p}=$ $0.0020)$ and the iron deficient $(*, p=0.0001)$ groups from pre-infusion to peak response. Diastolic pressure similarly increased from pre-infusion to peak response for both control (\#, p = 0.0040) and iron deficient (\#, p < $0.0001)$ groups when norepinephrine was infused. These observations are consistent with the vasoconstrictive effect of norepinephrine. Also, increased heart contractility is expected to increase peak systolic pressure. The diastolic pressure of iron deficient rats was significantly lower than controls both before $(*, \mathrm{p}=0.0131)$ and after $(*, \mathrm{p}=$ $0.0004)$ norepinephrine infusion. This is consistent with the idea of vascular remodeling to a larger arterial diameter with iron deficiency (discussed below), which could reduce the afterload against which the heart must work to eject blood.

\section{Experiment 2}

Representative aortas from control and iron deficient rats after one month on the respective diets are shown in figure 5, and mean aorta external diameter at $100 \mathrm{mmHg}$ pressure is illustrated in figure 6 . There was a significant duration effect $(\dagger, \mathrm{p}<0.0001)$, likely due to body growth. Overall, the diameter of aortas from iron deficient rats was greater than from control rats $(*, \mathrm{p}=0.0280)$. The regulation of lumenal diameter in large arteries is accomplished through the maintenance of shear stress along the arterial wall $[38,50-54]$. As blood flow through an artery increases, shear is also increased, and the endothelium releases nitric oxide for vasodilation [55]. Chronically, the arterial wall will remodel to a larger diameter to accommodate the increased flow [38]. While we did not measure arterial flow through these iron deficient arteries, the enhanced inotropic compensation to iron deficiency, combined with the enlarged aortic diameter, leads us to suspect a flow dependent mechanism for remodeling. Future investigations will be necessary to confirm this assertion.

Aortic distensibility, the increase in external diameter during stepwise internal pressure increases, is also shown in figure 6 . There is a significant group difference $(*, \mathrm{p}=$ 0.0101 ) with the iron deficient aortas more compliant than the controls overall. A decrease in collagen production with iron deficiency could account for this enhanced distensibility. It has been reported that collagen production is reduced in iron deficient hearts [40], but we are aware of no studies that have specifically examined alterations in collagen production in iron deficient arteries. Further research regarding this issue is warranted.

\section{Experiment 3}

Figure 7 shows the heart weight to body weight ratio for rats that received a daily intra-peritoneal injection of ei- 


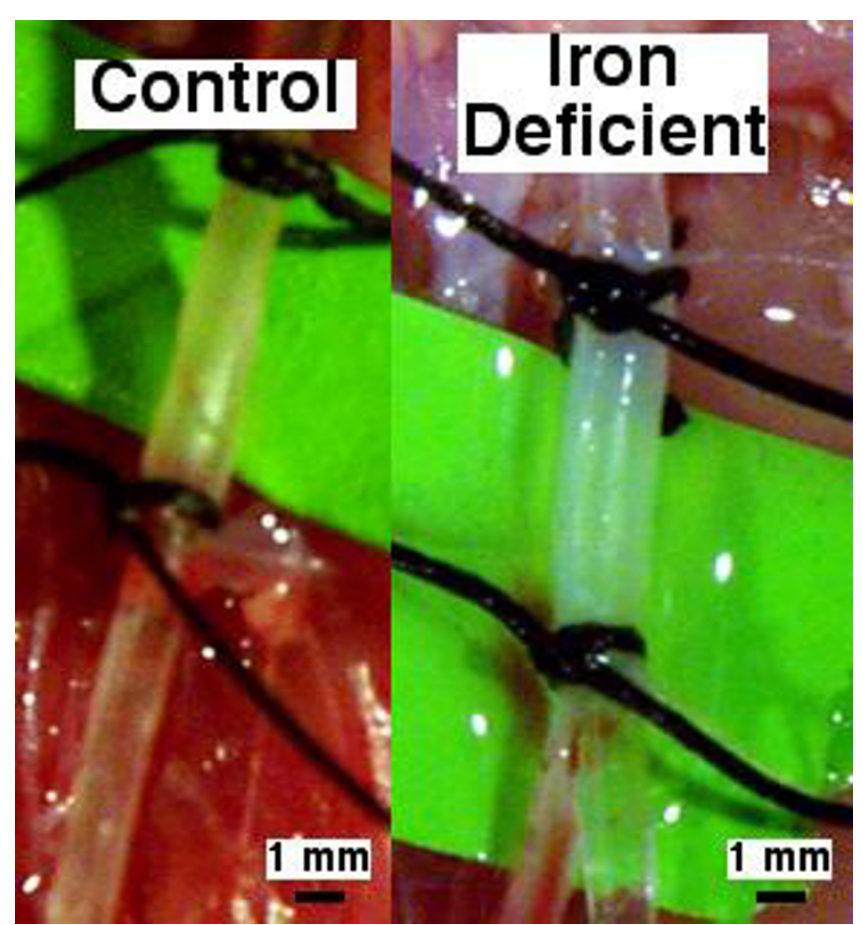

Figure 5

Control and Iron Deficient Aorta Images

ther the beta-blocker propanolol or saline for 1 month. This ratio was significantly greater in rats fed the iron deficient diet than controls $(*, p=0.0002)$. Clearly, iron deficient cardiac hypertrophy is not caused by chronic stimulation of beta-adrenergic receptors in the heart.

Many studies have shown that chronic intravenous infusion of norepinephrine is sufficient to cause hypertrophy, and that various forms of hypertrophy are linked to a decrease in either beta-adrenergic receptor density or a decreased responsiveness to beta-adrenergic stimulation $[46,48,49,56-63]$. Barth, for example, showed that norepinephrine infusion induced left ventricular hypertrophy that could be prevented by an adrenergic-receptor blocker [58]. It has been suggested that ornithine decarboxylase is a link between beta-adrenoreceptors and stimulation of tissue growth factor, which results in hypertrophy [64]. However, recent studies have focused on alpha-adrenergic reception as a mediator of cardiac hypertrophy [35], although some question the role of the alpha-adrenergic receptor as a hypertrophic mediator in vivo [34]. To date, no published studies of which we are aware have examined alpha-adrenergic reception and the development of cardiac hypertrophy with iron deficiency.

The literature surrounding norepinephrine and its role in the development of iron deficient hypertrophy documents the following facts: 1) prolonged iron deficiency
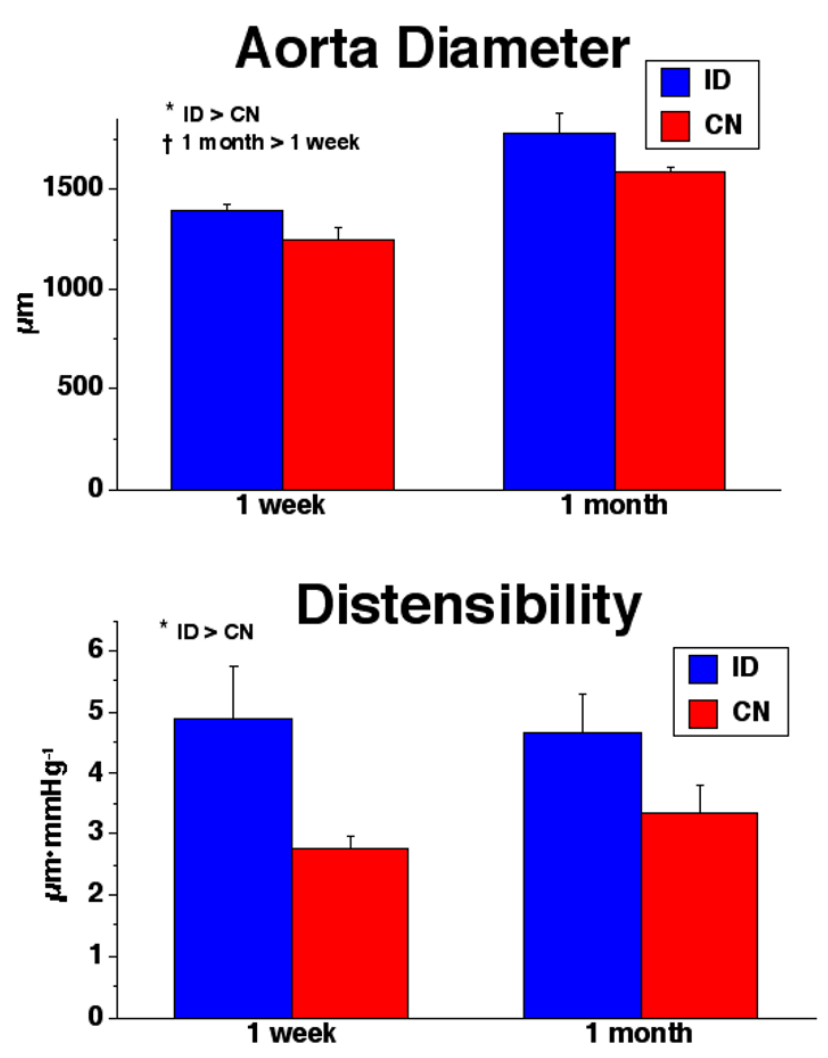

Figure 6

Aorta External Diameter and Distensibility

\section{Heart Mass/Body Mass}

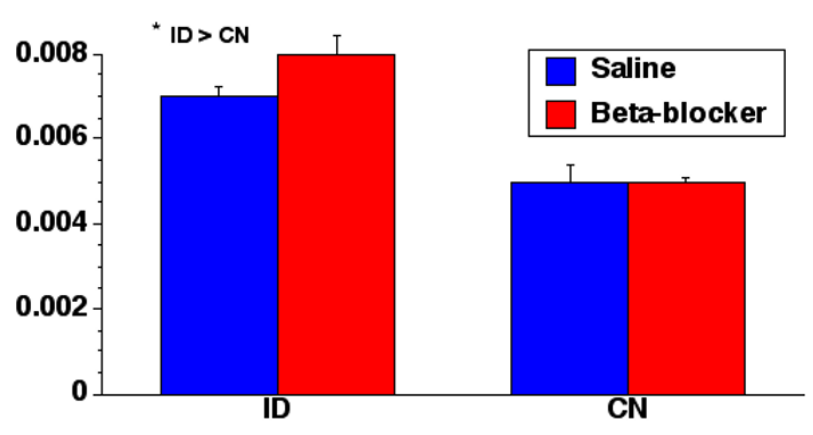

\section{Figure 7}

Heart Mass/Body Mass After Beta-blocker Treatment

causes cardiac hypertrophy $[11-17,23], 2)$ the pool of stored norepinephrine in the heart is decreased with iron deficiency $[17,21], 3)$ plasma and urine concentrations of norepinephrine are increased with iron deficiency [19$22,68]$, and 4) chronic administration of reserpine (which depletes norepinephrine) prevents the development of iron deficient hypertrophy [12], but not hypertrophy that results from aortic banding [23]. This, combined with 
other studies that relate chronic adrenergic stimulation to hypertrophy, led Rossi to the conclusion that iron deficiency hypertrophy was caused by chronic sympathetic stimulation. However, our finding that a daily injection of the beta-blocker propanolol does not prevent the development of iron deficient cardiac hypertrophy suggests that beta-adrenergic sympathetic stimulation may not be a causal agent in the development of hypertrophy. Future investigation is warranted into the potential alpha-adrenergic role in this hypertrophy.

\section{Conclusions}

The purpose of this study was to investigate cardiac and vascular responses associated with the development of iron deficiency. In our first experiment, we tested the hypothesis that the iron deficient heart would display an altered response to norepinephrine, the sympathetic nervous system neurotransmitter. In contrast to what has been seen with most cardiac disease states, we found that the iron deficient heart is hyper-sensitive to norepinephrine. This suggests an adaptive compensation to the depletion of the neurotransmitter stores in the heart sympathetic nerve terminals. Further, we found that contractility was enhanced, but heart rate was not. This would allow for the iron deficient animal to increase cardiac output through enhanced stroke volume, while maintaining the amount of time available for cardiomyocyte perfusion.

Our second experiment was designed to investigate whether vascular morphology would be altered with iron deficiency. Our results show an increase in abdominal aorta diameter, suggesting that a flow-dependent remodeling of the arterial wall occurred. Also, distensibility was significantly increased, which we suggest may be due to a reduction in arterial collagen. These morphological adjustments can be seen as a positive adaptation to simultaneously reduce afterload on the heart and improve blood flow to peripheral tissues.

Our final experiment was a simple test to determine if the beta-adrenergic antagonist propanolol would prevent hypertrophy. The failure of the beta-blocker to prevent hypertrophy suggests that, if the sympathetic nervous system is a causal agent in the development of this form of hypertrophy, the signaling mechanism is not mediated by the beta-adrenergic receptor.

In summary, much remains to be learned about this form of hypertrophy. Further experimentation may serve to elucidate not only the pathology of iron deficient cardiac hypertrophy, but other forms of this pathology as well.

\section{Materials and methods}

All procedures conducted in this experiment were consistent with "The American Physiological Society Guiding Principles for the Care and Use of Animals" [http:// www.the-aps.org/pub\%5Faffairs/humane/

pa_aps_guiding.htm] . 40 male CD (Sprague Dawley) rats (Charles River Laboratories, Raleigh, NC, [http:// www.criver.com] were randomly divided into two groups and placed on either a control (iron-replete) or iron-deficient diet (Dyets Inc., Bethlehem, PA, [http:// www.dyets.com] ) at 24 days of age. The control diet was a pelleted AIN-93G purified rodent diet [69]. The iron deficient diet was based on the AIN-93G standard, but with microcrystalline cellulose and a reagent grade mineral mixture free of ferric citrate. This diet provides $<5 \mathrm{ppm}$ iron. All rats were given constant access to the respective diets and distilled water, kept on a $12 \mathrm{~h}$ light cycle, and weighed weekly and just before each was sacrificed.

A total of 40 animals (20 iron deficient and 20 control) were utilized for three experiments. Experiments \# 1 and 2 used 30 rats after either 1 week or 1 month of the dietary manipulations, while experiment \#3 used the remaining 10 rats after 1 month on the diets.

\section{Experiment I: cardiovascular response to norepinephrine}

The purpose of this experiment was to determine whether iron deficient rats exhibit altered cardiac and vascular pressure responses to intravenous infusions of the sympathetic nervous system neurotransmitter norepinephrine. Intravenous infusions of physiological saline solution were used as a control. This experiment was a $2 \times 2$ factorial design, with diet (iron deficient vs. control) and duration ( 1 week vs. 1 month on the diets) as variables.

\section{Experimental procedure}

Rats were sedated by intra-muscular injection (right hamstring) of $65 \mathrm{mg} \cdot \mathrm{kg}^{-1}$ body mass ketamine hydrochloride. Three minutes later, they were anesthetized with 6.5 $\mathrm{mg} \cdot \mathrm{kg}^{-1}$ body mass xylazine. Adequate anesthesia was demonstrated by little or no withdrawal reflex to a toe pinch. Once anesthetized, one PE-50 (Becton-Dickinson) catheter filled with heparinized saline solution (131.9 $\mathrm{mM} \mathrm{NaCl}, 4.7 \mathrm{mM} \mathrm{KCl}, 2.0 \mathrm{mM} \mathrm{CaCl}_{2}, 1.17 \mathrm{mM} \mathrm{MgSO}_{4}$, $17.4 \mathrm{mM} \mathrm{NaHCO}_{3}, 50$ IU heparin sodium) was surgically implanted into the right carotid artery, and another into the left jugular vein.

Following catheterization and closure of the incision, the carotid catheter was connected to a pressure transducer (Cobe Model CDX III) and analog to digital conversion system (ETH-250 bridge/bio-amplifier used in bridge mode with an input gain of $100 \times$ and a $50 \mathrm{~Hz}$ filter, C.B. Sciences, Inc. and MacLab/4E analog to digital converter, A.D. Instruments, Inc.). The converter was connected via 
SCSI interface to an accelerated Power Mac 6100/66 computer (Apple Computer, Inc., Cupertino, CA); Chart software (Version 3.4.2, sampling every $0.01 \mathrm{~s}$ and set to accept a maximum input of $1 \mathrm{~V}$, A.D. Instruments, Inc.) was used to visualize the output. The pressure transducer system was calibrated by mercury manometer at the beginning of each experiment, and was found to be linear and consistent throughout the range of pressures measured.

One hundred microliters of saline solution was infused into the jugular vein catheter, and the cardiovascular response was recorded via the carotid pressure transducer until pressure stabilized near its baseline value. This procedure was repeated using $100 \mu \mathrm{L}$ of $1.52 \mathrm{mM}$ norepinephrine (in saline solution), and the arterial trace recorded.

\section{Data Treatment and Statistical Analysis}

Cardiovascular variables were analyzed immediately prior to infusion (pre-infusion) and at the maximal pressor response (peak response), $20 \mathrm{~s}$ after jugular infusion. Chart software was used to determine minimal (diastolic) and maximal (systolic) pressures and heart rate. Contractility $\left(\mathrm{dP} \bullet \mathrm{dt}^{-1}\right)$ was measured as the average slope between each pair of data points within the systolic pulse. Pulse pressure was calculated as the difference between systolic and diastolic pressures.

Analysis of Variance was performed using StatView software (Version 5.0.1, SAS Institute, Cary, NC), to determine diet (iron deficient vs. control) and duration (1 week vs. 1 month) effects. Paired t-tests were employed to determine significant changes from pre-infusion to peak response. Dependent variables were heart rate, contractility, systolic pressure, and diastolic pressure. Probabilities below 0.05 were accepted as significant for all statistical procedures throughout all experiments in this study.

\section{Experiment 2: remodeling of abdominal aorta}

The purpose of this experiment was to explore alterations in vascular morphology of iron deficient rats, using the abdominal aorta as a representative artery. This experiment used the same rats as in experiment \#1, and was also $2 \times 2$ design with diet and duration factors.

\section{Experimental Procedures}

After experiment 1 , the rats were decapitated. The abdominal aorta was carefully exposed, and two catheters were surgically implanted. The first was inserted just caudal to the superior mesenteric artery, and the other just cranial to the inferior mesenteric artery. The superior catheter was used for stepwise saline infusions at a range of pressures from $0-120 \mathrm{mmHg}$. Exact pressures were measured via a pressure transducer attached to the inferior catheter. Digital images of the abdominal aorta were taken at each pressure with a Kodak DC120 digital camera coupled to a dissecting microscope (Leica MZ6). The external diameter of the abdominal aorta was measured using NIH image software (Version 1.62, National Institutes of Health, Bethesda, MD) on an accelerated Power Mac 7500/100 (Apple Computer, Cupertino, Ca). The system was calibrated by using the digital image of a ruler at the same magnification.

\section{Data Treatment and Statistical Analysis:}

Regression analysis was performed using aorta external diameter and inflation pressure as dependent and independent variables, respectively. Distensibility was estimated as the slope of the regression line for each individual animal. The external diameter of the abdominal aorta at $100 \mathrm{mmHg}$ pressure was also estimated from the individual regression equations. Analysis of Variance was then performed on distensibility and $100 \mathrm{mmHg}$ external diameter.

\section{Experiment 3: propanolol effects on heart morphology}

The purpose of this experiment was to see if a daily injection of the beta-blocker propanolol inhibits the cardiac hypertrophy that is associated with iron deficiency in weanling rats. This experiment was a $2 \times 2$ design, using diet and drug (saline vs. propanolol) as factors.

\section{Experimental procedures}

Ten rats ( 5 iron deficient and 5 control) were given a daily intra-peritoneal injection of either propanolol $(50 \mathrm{mg} \bullet \mathrm{kg}$ 1 body mass per day) or saline solution. After 1 month, the rats were sacrificed by decapitation and the hearts were carefully extracted and weighed.

\section{Data treatment and statistical analysis}

The heart mass to body mass ratio was calculated, and Analysis of Variance was performed as above.

\section{Acknowledgments}

We gratefully acknowledge the financial support of the Henson School of Science and Technology at Salisbury State University for these experiments.

\section{References}

I. Sullivan JL: Iron and the sex difference in heart disease risk. Lancet I 98I, I:I 293

2. Williams RE, Zweier JL, Flaherty JT: Treatment with deferoxamine during ischemia improves functional and metabolic recovery and reduces reperfusion-induced oxygen radical generation in rabbit hearts. Circulation 1991, 83:1006

3. van der Kraaij AMM, Mostert LJ, van Eijk HG, Koster JF: Iron-load increases the susceptibility of rat hearts to oxygen reperfusion damage: Protection by the antioxidant $(+)-$ cyanidanol-3 and deferoxamine. Circulation 1988, 78:442

4. Roest M, van der Schouw TT, de Valk B, Marx JJM, Tempelman MJ, de Groot PG, Sixma JJ, Dirk Banga J: Heterozygosity for a heriditary hemochromatosis gene is associated with cardiovascular death in women. Circulation 1999, 100:1268

5. Tuomainen T-P, Kontula K, Nyyssönen K, Lakka TA, Heliö T, Salonen $\mathrm{JT}$ : Increased risk of acute myocardial infarction in carriers of the hemochromatosis gene cys282tyr mutation. Circulation 1999, 100:1274 
6. Ascherio A, Rimm EB, Giovannucci E, Willett WC, Stampfer MJ: Blood donations and risk of coronary heart disease in men. Circulation 200I, 103:52

7. McCord JM: Is iron sufficiency a risk factor in ischemic heart disease? Circulation 1991, 83:1।12

8. Sullivan JL: Iron and the genetics of cardiovascular disease. Circulation 1999, 21:1260

9. Sullivan JL: Iron therapy and cardiovascular disease. Kidney Int Suppl 1999, 69:SI35

10. Sullivan JL: Misconceptions in the debate on the iron hypothesis. J Nutr Biochem 200 I, I 2:33

II. Rossi MA, Carillo SV: Electron microscopic study on the cardiac hypertrophy induced by iron deficiency anaemia in the rat. BrJ Exp Pathol 1983, 64:373

12. Rossi MA, Carillo SV: Pathogenesis of cardiac hypertrophy in iron deficiency anaemia: the role of noradrenaline. $\mathrm{Br} J \operatorname{Exp}$ Pathol 1 982, 63:269

13. Rossi MA, Carillo SV, Oliveira JSM: The effect of iron deficiency anemia in the rat on catecholamine levels and heart morphology. Cardiovas Res 198I, 15:313

14. Tanne Z, Coleman R, Nahir M, Shomrat D, Finberg JPM, Youdim $\mathrm{MBH}$ : Ultrastructural and cytochemical changes in the heart of iron-deficient rats. Biochem Pharmacol 1994, 47:1759

15. Olivetti G, Lagrasta C, Quaini F, Ricci R, Moccia G, Caprasso JM, Anversa $P$ : Capillary growth in anemia-induced ventricular wall remodeling in the rat heart. Circ Res 1989, 65:1/82

16. Olivetti G, Quaini F, Lagrasta C, Ricci R, Tiberti G, Capasso JM, Anversa $P$ : Myocyte cellular hypertrophy and hyperplasia contribute to ventricular wall remodeling in anemia-induced cardiac hypertrophy in rats. Am J Pathol 1992, 14 1:227

17. Medeiros DM, Beard JL: Dietary iron deficiency results in cardiac eccentric hypertrophy in rats. Proc Soc Exp Biol Med 1998, 218:370

18. Whittaker P, Mahoney AW, Hendricks DG: Effect of iron-deficiency anemia on percent blood volume in growing rats. $J$ Nutr 1984, 1 1 4:1 137

19. Dillman E, Johnson DG, Martin J, Mackler B, Finch CA: Catecholamine elevation in iron deficiency. Am J Physiol I979, 237:R297

20. Beard JL, Tobin BW, Smith SM: Effects of iron repletion and correction of anemia on norepinephrine turnover and thyroid metabolism in iron deficiency. Proc Soc Exp Biol Med 1990, 1 93:306

21. Beard JL, Tobin B, Smith SM: Norepinephrine turnover in iron deficiency, at three environmental temperatures. Am J Physiol 1988, 255:R90

22. Borel MJ, Smith SH, Brigham DE, Beard JL: The impact of varying degrees of iron nutriture on several functional consequences of iron deficiency in rats. J Nutr 1991, I $21: 729$

23. Rossi MA, Carillo SV: Does norepinephrine play a central causative role in the process of cardiac hypertrophy? Am Heart J 1985, 109:622

24. Zelis R, Clemson B, Baily R, Davis D: Regulation of tissue noradrenaline in the rat myocardial infarction model of chronic heart failure. Cardiovasc Res 1992, 26:933

25. Daly PA, Sole MJ: Myocardial catecholamines and the pathophysiology of heart failure. Circulation 1990, 82:1-35

26. Hammond HK, Roth DA, Insel PA, Ford CE, White FC, Maisel AS, Ziegler MG, Bloor CM: Myocardial beta-adrenergic receptor expression and signal transduction after chronic volumeoverload hypertrophy and circulatory congestion. Circulation 1992, 85:269

27. Kouchi I, Zolk O, Jockenhovel F, Itter G, Linz W, Cremers B, Bohm $M$ : Increase in G(i alpha) protein accompanies progression of post-infarction remodeling in hypertensive cardiomyopathy. Hypertension 2000, 36:42

28. Schafer M, Frischkopf K, Taimor G, Piper HM, Schulter KD: Hypertrophic effect of selective beta(I)-adrenoceptor stimulation on ventriculat cardiomyocytes from adult rat. Am J Physiol Cell Physiol 2000, 279:C495

29. Zuo P, Izawa H, Ishiki R, Noda A, Nishizawa T, Shigemura K, Nagata $K$, Iwase $M$, Yokota M: Different beta-adrenergic regulation of myocardial contraction and relaxation between apical and nonobstructive hypertrophic cardiomyopathy. Am Heart J 2000, I 40:329

30. Pei J, Yu X, Fung M, Zhou J, Cheung C, Wong N, Leung M, Wong T: Impaired G(s)alpha and adenylyl cyclase cause beta-adreno- ceptor desensitization in chronically hypoxic rat hearts. Am J Physiol Cell Physiol 2000, 279: Cl455

31. Du X, Gao X, Jennings G, Dart A, Woodcock E: Preserved ventricular contractility in infarcted mouse heart overexpressing beta(2)-adrenergic receptors. Am J Physiol Heart Circ Physiol 2000, 279: $\mathrm{H} 2456$

32. Nagata K, Communal C, Lim C, Jain M, Suter T, Eberli F, Satoh $N$, Colucci W, Apstein C, Liao R: Altered beta-adrenergic signal transduction in nonfailing hypertrophied myocytes from Dahl salt-sensitive rats. Am J Physiol Heart Circ Physiol 2000 , 279: $\mathrm{H} 2502$

33. Akers W, Cross A, Speth R, Dwoskin L, Cassis L: Renin-angiotensin system and sympathetic nervous system in cardiac pressure-overload hypertrophy. Am J Physiol Heart Circ Physiol 2000, 279:H2797

34. Lin F, Owens WA, Chen S, Stevens ME, Kesteven S, Arthur JF, Woodcock EA, Fenely MP, Graham RM: Targeted alpha(I A)-adrenergic receptor overexpression induces enhanced cardiac contractility but not hypertrophy. Circ. Res. 200I, 89:343

35. laccarino G, Keys J, Rapacciuolo A, Shotwell K, Lefkowitz R, Rockman $H$, Koch W: Regulation of myocardial betaARKI expression in catecholamine-induced cardiac hypertrophy in trangenic mice overexpressing alpha I B-adrenergic receptors. J Am Coll Cardiol 200I, 38:534

36. Ostman-Smith I: Cardiac sympathetic nerves as the final common pathway in induction of adaptive cardiac hypertrophy. Clin Sci 198I, 6I:265

37. Varat M, Adolph R, Fowler N: Cardiovascular effects of anemia. Am Heart J 1972, 83:4 I5

38. Kamiya $A$, Togawa $T$ : Adaptive regulation of wall shear stress to flow change in the canine carotid artery. Am J Physiol Heart Circ 1980, 239: HI 4

39. O'Dell B: Roles for iron and copper in connective tissue biosynthesis. Philos Trans R Soc Lond B Biol Sci 198I, 14:91

40. Chvapil M, Hurych J, Ehrilchova $E$ : The effect of iron deficiency on the synthesis of collagenous and non-collagenous proteins in wound granulation tissue and in the heart of rats. Exp Med Surg 1968, 26:52

4I. Pettersen JC, Morrissey RL, Saunders DR, Pavkov KL, 3rd LLG, Turnier JC, Matheson DW, Schwartz DR: A 2-year comparison study of Crl:CD Br and Hsd:Sprague-Dawley SD rats. Fundam Appl Toxicol 1996, 33:196

42. Klinger MM, MacCarter GD, Boozer CN: Body weight and composition in the Sprague Dawley rat: comparison of three outbred sources. Lab Anim Sci 1996, 46:67

43. Jenkins JE, Medieros DM: Diets containing corn oil, coconut oil, and cholesterol alter ventricular hypertrophy, dilatation and function in hearts of rats fed copper-deficient diets. J Nutr 1993, I 23:1150

44. Homcy C, Vatner S, Vatner D: Beta-adrenergic receptor regulation in the heart in pathophysiologic states: abnormal adrenergic responsiveness in cardiac disease. Ann Rev Physiol 1991, 53:137

45. Patel M, Stewart J, Loud A, Anversa P, Wang J, Fiegel L, Hintze T: Altered function and structure of the heart in dogs with chronic elevation in plasma norepinephrine. Circulation I99I, 84:209 I

46. Engelhardt S, Hein L, Weismann F, Lohse MJ: Progressive hypertrophy and heart failure $\mathbf{n}$ beta 1 -adrenergic receptor transgenic mice. Proc Natl Acad Sci USA 1999, 96:7059

47. Mukherjee R, Spinale FG: L-type calium channel abundance and function with cardiac hypertrophy and failure: a review. J Mol Cell Cardiol 1998, 30:1899

48. Tse J, Huang MW, Leone RJ, Weiss HR, He YQ, Scholz PM: Down regulation of myocardial beta I-adrenoreceptor signal transduction system in pacing-induced failure in dogs wih aortic stenosis-induced left ventricular hypertrophy. Mol Cell Biochem 2000, 205:67

49. Sheridan DJ, Auteltano DJ, Wang B, Percy E, Woodcock EA, Du XJ: Beta2-adrenergic receptor overexpression driven by alphaMHC promoter is downregulated in hypertrophied and failing myocardium. Cardiovasc Res 2000, 47:133

50. Furchgott RF: Role of endothelium in responses in vascular smooth muscle. Circ Res 1983, 53:557

51. Langille BL, O'Donnell F: Reductions in arterial diameter produced by chronic decreases in blood flow are endotheliumdependent. Science 1986, 231:405 
52. Langille BL, Bendeck MP, Keeley FW: Adaptations of carotid arteries of young and mature rabbits to reduced carotid blood flow. AJP 1989, 256:H93)

53. Miller VM, Vanhoutte PM: Enhanced release of endothelium-derived factor(s) by chronic increases in blood flow. Am J Physiol 1 988, 255:H446

54. Guyton JR, Hartley C]: Flow restriction of one carotid artery in juvenile rats inhibits growth of arterial diameter. Am J Physiol 1 985, 248: H540

55. Palmer RMJ, Ferrige AG, Moncada S: Nitric oxide release accounts for the biological activity of endothelium-derived relaxing factor. Nature 1987, 327:524

56. Cho MC, A R, Koch WJ, Kobayashi Y, LR J, Rockman HA: Defective beta-adrenergic receptor signaling precedes the development of dilated cardiomyopathy in transgenic mice with calsequestrin overexpression. J Biol Chem I 999, 274:2225 I

57. Calls J, Cases A, S. L, N. E, Pare JC, M. A, Jimenez W, F. R-F: Betaadrenergic receptor density and function in left ventricular hypertrophy in young essential hypertensives. J Hum Hypertens 2000, 1 4:17

58. Barth W, Denten A, Bauer M, Reinohs M, Leicht M, Zimmer HG: Differential remodeling of the left and right heart after norepinephrine treatment in rats: studies on cytokines and collagen. J Mol Cell Cardiol 2000, 32:273

59. Xu X, Rials SJ, Wu Y, Liu T, Marinchak RA, Kowey PR: Effects of captopril treatment of renovascular hypertension on betaadrenergic modulation of L-type $\mathbf{C a}(2+)$ current. J Pharmacol Exp Ther 2000, 292:196

60. Communal C, Ribuot C, Durand A, Demenge P: Myocardial betaadrenergic reactivity in volume overload-induced cardiac hypertrophy in the rat. Fundam Clin Pharmacol 1998, 12:411

61. Communal C, Ribuot C, Durand A, Demenge P: Myocardial betaadrenergic reactivity in pressure overload-induced cardiac hypertrophy in the rat. Fundam Clin Pharmacol 1998, I 2:590

62. Leon-Velarde F, Bourin MC, Germack R, Mohammadi K, Crozatier B, Richalet JP: Differential alterations in cardiac adrenergic signaling in chronic hypoxia or norepinephrine infusion. Am / Physiol Regul Integr Comp Physiol 2001, 280:R274

63. Schotten U, Filzmaier K, Borghardt B, Kulka S, Schoendube F, Schmacher C, Hanrath P: Changes of beta-adrenergic signaling in compensted human cardiac hypertrophy depend on the underlying disease. Am / Physiol Heart Circ Physiol 2000, 278: H2076

64. Schluter KD, Frischkopf K, Flesch M, Rosenkranz S, Taimor G, Piper HM: Central role for ornithine decarboxylase in beta-adrenoreceptor mediated hypertrophy. Cardiovasc Res 2000, 45:410

65. Martinez ML, Fernandez-Tome P, Lopez-Miranda V, Colado MI, Delgado $C$ : Modulation of adrenergic receptors during left ventricular hypertrophy development after regression by captopril. J Cardiovasc Pharmacol 1999, 127:1012

66. Meissner A, Min JY, Simon R: Effects of angiotensin II on intropy and intracellular $\mathrm{Ca2}+$ handling in normal and hypertrophied rat myocardium. J Mol Cell Cardiol 1998, 30:2507

67. Grimm D, Holmer SR, Riegger GA, Kromer EP: Effects of beta-receptor blockade and angiotensin II type I receptor antagonism in isoproterenol-induced heart failure. Cardiovas Pathol 1999, 8:315

68. Dallman PR, Refino CA, Yland MJ: Sequence of development of iron deficiency in the rat. Am / Clin Nutr 1982, 35:671

69. Reeves PG, Nielsen FH, Fahey GC]: AIN-93 purified diets for laboratory rodents: Final report of the American Institute of Nutrition ad hoc writing committee on the reformulation of the AIN-76A rodent diet. J Nutr 1993, I 23:1939

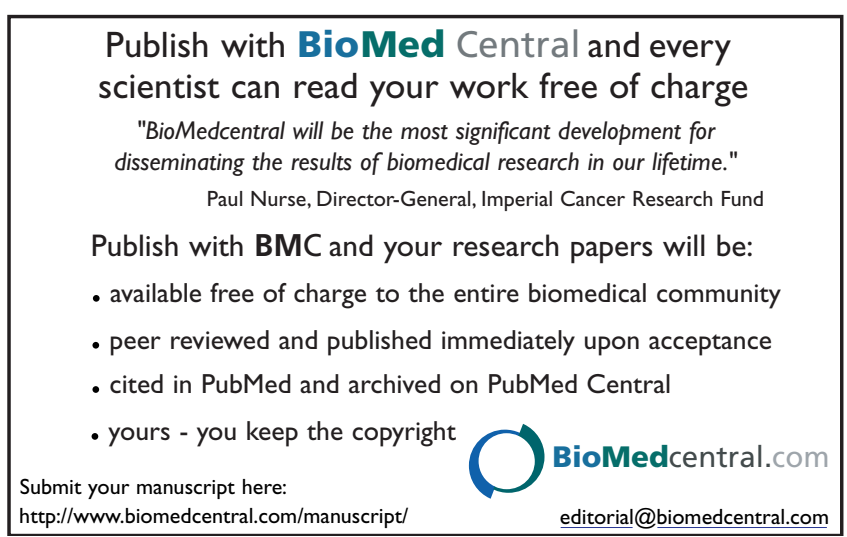

